\title{
High Kellgren-Lawrence Grade and Bone Marrow Lesions Predict Worsening Rates of Radiographic Joint Space Narrowing; The SEKOIA Study
}

\author{
Mark H. Edwards, Camille Parsons, Olivier Bruyère, Forence Petit Dop, Roland Chapurlat, \\ Frank W. Roemer, Ali Guermazi, Souhil Zaim, Harry Genant, Jean-Yves Reginster, \\ Elaine M. Dennison, Cyrus Cooper, and the SEKOIA Study Group
}

ABSTRACT. Objective. Determinants of radiographic progression in osteoarthritis (OA) are poorly understood. We investigated which features on baseline magnetic resonance imaging (MRI) acted as predictors of change in joint space width (JSW).

Methods. A total of 559 men and women over the age of 50 years with clinical knee OA [Kellgren-Lawrence (KL) grade 2-3] were recruited to the placebo arm of the SEKOIA study (98 centers; 18 countries). Minimal tibiofemoral joint space and KL grade on plain radiograph of the knee were assessed at baseline and at yearly followup up to 3 years. In a subset, serial knee MRI examinations were performed. Individuals with a bone marrow lesion (BML) $\geq$ grade 2 at the tibiofemoral joint at baseline were classified as BML-positive. Relationships between change in JSW and risk factors were assessed using linear regression.

Results. The mean age of study participants was 62.8 (SD 7.5) years and 73\% were female; $38.6 \%$ had BML. Mean baseline JSW was $3.65 \mathrm{~mm}$. This reduced by $0.18(0.30) \mathrm{mm} / \mathrm{year}$ in men and 0.13 $(0.23) \mathrm{mm} /$ year in women. Those with BML had a significantly higher rate of annualized change in JSW; this relationship remained robust after adjustment for age, sex, and baseline KL grade [ $\beta=$ $-0.10(95 \% \mathrm{CI}-0.18,-0.02) \mathrm{mm} / \mathrm{yr}]$. Age, sex, baseline KL grade, and other MRI findings did not influence the rate of change in JSW.

Conclusion. The rate of change in JSW was similar in men and women. BML on knee MRI predicted the rate of radiographic change in JSW. This relationship was independent of age, sex, and baseline KL grade. (First Release January 15 2016; J Rheumatol 2016;43:657-65; doi:10.3899/jrheum.150053)

Key Indexing Terms:

OSTEOARTHRITIS

KNEE

PROGRESSION

NATURAL HISTORY

MAGNETIC RESONANCE IMAGING

RADIOGRAPHIC JOINT SPACE NARROWING

From the MRC Lifecourse Epidemiology Unit, University of Southampton Southampton, UK, Department of Public Health and Health Economics, University of Liege, Liege, Belgium; Innovative Therapeutic Pole of Rheumatology, Servier, Surenes, France; INSERM UMR 1033, Service de Rhumatolgie et Pathologie Osseuse, Hôpital Edouard Herriot, Université de Lyon, Lyon, France; Quantitative Imaging Center, Department of Radiology, Boston University School of Medicine, Boston, Massachusetts, USA; Department of Radiology, University of Erlangen-Nuremburg, Erlangen, Germany; Synarc, San Francisco, California, USA; Department of Public Health and Health Economics, University of Liege; NIHR Biomedical Research Centre, University of Southampton and University Hospital Southampton NHS Foundation Trust, Southampton General Hospital; and NIHR Musculoskeletal Biomedical Research Unit, Nuffield Department of Orthopaedics, Rheumatology and Musculoskeletal Sciences, University of Oxford, Oxford, UK

Supported by the Medical Research Council of Great Britain; Arthritis Research UK; and the International Osteoporosis Foundation; and by the National Institute of Health Research Nutrition Biomedical Research Centre, University of Southampton and the National Institute of Health Research Musculoskeletal Biomedical Research Unit, University of Oxford. Dr. Edwards is supported by an Arthritis Research UK Clinical PhD Studentship.

M.H. Edwards, MD, PhD; C. Parsons, MSc, MRC Lifecourse

Epidemiology Unit, University of Southampton; O. Bruyère, PhD,
Department of Public Health and Health Economics, University of Liege; F. Petit Dop, PhD, Innovative Therapeutic Pole of Rheumatology; R. Chapurlat, MD, PhD, INSERM UMR 1033, Service de Rhumatolgie et Pathologie Osseuse, Hôpital Edouard Herriot, Université de Lyon; F.W. Roemer, MD, Quantitative Imaging Center, Department of Radiology, Boston University School of Medicine; Department of Radiology, University of Erlangen-Nuremburg; A. Guermazi, MD, PhD, Quantitative Imaging Center, Department of Radiology, Boston University School of Medicine; S. Zaim, MD, Synarc; H. Genant, MD, Synarc; J-Y. Reginster, $M D, P h D$, Department of Public Health and Health Economics, University of Liege; E.M. Dennison, MD, PhD, MRC Lifecourse Epidemiology Unit, University of Southampton; Victoria University; C. Cooper, FMedSci, MRC Lifecourse Epidemiology Unit, University of Southampton; NIHR Biomedical Research Centre, University of Southampton and University Hospital Southampton NHS Foundation Trust, Southampton General Hospital; NIHR Musculoskeletal Biomedical Research Unit, Nuffield Department of Orthopaedics, Rheumatology and Musculoskeletal Sciences, University of Oxford, Oxford, UK.

C. Parsons and Dr. Edwards are joint first authors of this report. Address correspondence to Prof. C. Cooper, MRC Lifecourse Epidemiology Unit (University of Southampton), Southampton General Hospital, Southampton,SO166YD,UK.E-mail: cc@mrc.soton.ac.uk Accepted for publication September 11, 2015.

Personal non-commercial use only. The Journal of Rheumatology Copyright @ $\odot$ 2016. All rights reserved 
Osteoarthritis $(\mathrm{OA})$ is a progressive disease of synovial joints that represents failed repair of damage. It is a substantial public health problem as it is the fifth largest cause of disability in older adults in the US ${ }^{1}$ and is associated with a huge economic burden. Involvement of large joints of the lower limb, such as the knee, has been shown to significantly affect mobility.

Despite this burden, the natural history of OA is not well understood. Disease progression is a complex process involving the joint structure as a whole, usually occurring slowly and irreversibly over many years. To optimize OA management, it is important to increase our knowledge regarding the predictors of progression, particularly if modifiable. There are few factors conclusively shown to predict progression of knee OA and many studies have provided conflicting results ${ }^{2}$. The observational literature has suggested the presence of generalized OA is related to faster disease progression ${ }^{3,4}$. However, body mass index $(\mathrm{BMI})^{3,4,5,6,7}$, age $^{4,6,7,8,9}$, and sex $\mathrm{x}^{3,4,6,7,8,9}$ have shown inconsistent relationships, although there is evidence the etiology of OA differs in men and women ${ }^{10}$.

More recently, studies have embarked upon defining the role of magnetic resonance imaging (MRI) both in phenotyping and in predicting progression in $\mathrm{OA}^{11}$, with bone marrow lesions (BML) of particular interest. These are regions of subchondral bone that show ill-defined high signal intensity on fluid-sensitive fat-suppressed spin-echo sequences on $\mathrm{MRI}^{12,13}$, and that histologically correlate with bone marrow edema, fibrosis, necrosis, and trabecular abnormalities ${ }^{14}$. Studies investigating relationships between BML and clinical symptoms have varied in their conclusions, although some associations between BML and joint pain in knee OA have been identified ${ }^{15,16,17,18,19}$. Further, longitudinal studies have suggested that their presence may predict progression of cartilage defects ${ }^{20,21,22}$ and perhaps cartilage loss assessed radiographically. In a study of US veterans with symptomatic knee OA, Felson, et al concluded that bone marrow edema is a potent predictor of radiological progression of knee $\mathrm{OA}^{23}$.

We investigated these possible associations in a second study, which considered determinants of OA progression through assessment of knee joint space width (JSW) at yearly intervals, using the control arm of an international, multicenter, randomized controlled trial of therapy for knee OA.

\section{MATERIALS AND METHODS}

Study design and patients. Our study uses data from individuals randomized to the placebo arm of the 3 -year SEKOIA trial $(n=559)^{24}$. The study was performed in 98 centers in 18 countries, the first patient visit was in early 2006, and recruitment ended in 2008. At inclusion, patients were randomly allocated to 3 treatment groups (strontium ranelate 1 or $2 \mathrm{~g} /$ day or placebo), with balanced randomization stratified by center and by sex (block size, 3 ). Pain score was measured by visual analog scale (VAS); physical activity level was assessed by the question, "Does the patient do regular physical activity?"

Overall selection criteria included ambulatory white men and women age $>50$ years with knee OA as defined by the American College of Rheumatology criteria ${ }^{25}$; pain on at least half the days in the previous month (intensity $\geq 40 \mathrm{~mm}$ on 100 -mm VAS); knee Kellgren-Lawrence $(\mathrm{KL})^{26}$ grade 2 or 3 ; and JSW between 2.5 and $5 \mathrm{~mm}$ with predominant knee OA of the medial tibiofemoral compartment

Exclusion criteria included recent intraarticular injection (glucocorticoids within last 3 mo or hyaluronic acid within last $6 \mathrm{mo}$ ), knee prosthesis, clinical deformities, secondary knee OA, previous treatments acting on cartilage or bone metabolism (e.g., oral or intravenous bisphosphonates within the last year, teriparatide or raloxifene within the last 7 days, and oral glucosamine $\geq 1500 \mathrm{mg}$ /day and chondroitin sulfate within the last $3 \mathrm{mo}$ ), and a medical history of or high risk of venous thromboembolism (contraindication for strontium ranelate)

Radiographic measures. Radiographs were obtained at the time of selection and then annually on the target knee, using a standardized technique ${ }^{24}$. The radiographer recorded a fixed-flexion posteroanterior view (fixed angle $10^{\circ}$ ), using a SynaFlexer ${ }^{\mathrm{TM}}$ positioning frame (Synarc Inc., San Francisco, CA, $\mathrm{USA}^{27}$. All radiographs were measured centrally (INSERM UMR 1033 Lyon, France) by a single reader blinded to treatment allocation and patient identity. Each blinded post-baseline image was measured in comparison with the inclusion image to optimize reproducibility and sensitivity $28,29,30$ Minimal JSW (mm) at the medial tibiofemoral compartment was measured using a standardized computer-assisted method ${ }^{31}$. A second reading was performed by a single reader in another center (Liege, Belgium), independent of the first center, using the same method; interreader reproducibility was excellent [intraclass correlation coefficients (ICC) for joint space width > 0.90]. Intrareader reproducibility was evaluated using ICC at yearly intervals, using 70 knee radiographs unlinked to the study, and was found to be excellent (ICC for joint space width $>0.90)^{28}$

MRI assessment. MRI of the target knee was performed at inclusion at one of 36 validated clinical centers in a subset of patients $(n=176)$. The MRI scans obtained were read centrally at Synarc, San Francisco, CA, USA, using the whole organ magnetic resonance imaging score ${ }^{32}$. MRI scans were assessed for the presence of bone marrow edema, cartilage morphology abnormalities, areas of high cartilage signal, cysts, bursae, ligament abnormalities, or osteophytes. Those knees with a BML grade $\geq 2$ in any area within the tibiofemoral joint were categorized as BML-positive; this was due in part to the small number of study subjects with a BML grade of 3 .

Ethical approval for the study was granted by the ethics committee or institutional review board of every site and all participants gave written informed consent before randomization in accord with the Declaration of Helsinki ${ }^{33}$

Statistical analysis. All participants $(\mathrm{n}=559)$ were included in crosssectional analyses at baseline. Individuals with followup measurements of joint space were included in longitudinal analyses $(n=472)$. Analyses of BML were limited to the subset of men and women who had undergone MRI scanning. Participants' continuous characteristics were checked for normality and summarized using means and standard deviations (SD) and counts and percentages were used for binary and categorical characteristics. JSW (mm/year of followup) was calculated for each participant as the difference between last recorded JSW and baseline JSW, divided by the number of years the patient remained within the study. The primary analysis used linear regression to assess the relationship between clinical variables and (1) change in JSW (mm/year of followup) and (2) JSW measurement at baseline. The following risk factors were considered in our analyses: age, sex, BMI, height, weight, smoking status, alcohol use, hand OA, hip OA, and KL grade, as predictors of standardized yearly change in JSW. These analyses were completed in men and women separately and in the cohort as a whole, with and without adjustment for age and sex and mutual adjustment for the other clinical variable (BML or KL grade as appropriate). All analyses were undertaken using Stata 12 .

\section{RESULTS}

Table 1 shows the descriptive characteristics of the 559 men

Personal non-commercial use only. The Journal of Rheumatology Copyright (C) 2016. All rights reserved 
Table 1. Demographic population statistics.

\begin{tabular}{llcc}
\hline Variables & Men, $\mathrm{n}=167$ & Women, $\mathrm{n}=392$ & All, $\mathrm{n}=559$ \\
\hline Age, yrs, mean (SD) & $63.8^{*}(7.8)$ & $62.3^{*}(7.3)$ & $62.8(7.5)$ \\
Body mass index (BMI), $\mathrm{kg} / \mathrm{m}^{2}$, mean (SD) & $29.8(4.1)$ & $29.8(5.5)$ & $29.8(5.1)$ \\
$\quad$ BMI obese, $\mathrm{n}(\%)$ & $67(40)$ & $178(45)$ & $245(44)$ \\
Severity of knee osteoarthritis, mean (SD) & & & \\
$\quad$ Joint space width at baseline, mm & $3.65^{* *}(0.85)$ & $3.44 * *(0.82)$ & $3.51(0.83)$ \\
$\quad$ Joint space width at end of study, mm & $3.20(1.06)$ & $3.12(0.98)$ & $3.15(1.00)$ \\
$\quad$ Standardized yearly change, mm & $-0.18(0.30)$ & $-0.13(0.23)$ & $-0.15(0.26)$ \\
Kellgren-Lawrence scale score, $\mathrm{n}(\%)$ & & & \\
2 & $103(62)$ & $247(63)$ & $350(63)$ \\
3 & $64(38)$ & $145(37)$ & $209(37)$ \\
MRI findings (subpopulation of 176$), \mathrm{n}(\%)$ & & & \\
$\quad$ Bone marrow lesions & $20(43)$ & $48(37)$ & $68(39)$ \\
$\quad$ Cartilage morphology & $46(96)$ & $120(93)$ & $166(94)$ \\
Cartilage signal & $6(13)$ & $22(17)$ & $115(65)$ \\
Cyst bursa & $34(71)$ & $81(63)$ & $24(14)$ \\
Ligament abnormalities & $10(21)$ & $14(11)$ & $173(98)$ \\
$\quad$ Osteophytes & $47(98)$ & $126(98)$ & \\
\hline
\end{tabular}

Difference between men and women $* \mathrm{p}<0.05 ; * \mathrm{p}<0.01$.

and women studied. Their mean age was 62.8 (SD 7.5) years and $44 \%$ of them were obese; and the median followup duration was 35.5 months (range $0-39.8 \mathrm{mo}$ ). Men and women differed significantly in regard to mean age, men being older on average than women; however, men and women had a similar mean BMI at around $29 \mathrm{~kg} / \mathrm{m}^{2}$. Physical activity habit, frequency, and hours per week were found not to be significantly associated with progression of OA. Therefore physical activity was not included as a confounder within the analyses.

Among indices of disease severity, the participants' mean JSW at baseline was 3.51 (SD 0.83) mm, falling to 3.15 (SD $1.00) \mathrm{mm}$ by the end of the study, with an annualized mean JSW loss of 0.15 (SD 0.26) mm/year. At baseline, women had significantly narrower joint space than men. Of the total study population, $63 \%$ were classified with a KL grade 2 and $37 \%$ with KL grade 3, with little difference in these proportions between men and women. On MRI, the majority of participants were found to have cartilage morphology and osteophytes; however, no statistical differences were found between MRI characteristics in men or women, as shown in Table 1. Those with MRI scans were found to be taller and slightly older and smoked less; otherwise, demographic characteristics of those within the MRI subpopulation did not differ from those who did not have MRI scans. The baseline BML characteristics of participants are shown in Table 2. Just over one-third (38.6\%) of those studied had BML. Age and BMI did not differ significantly by BML status. WOMAC (Western Ontario and McMaster Universities Osteoarthritis Index) scores at baseline were higher in those with BML but, like VAS knee pain scores, did not differ significantly.

Figure 1 illustrates mean JSW at baseline and each study timepoint according to sex and baseline KL grade. At
Table 2. Demographic and clinical features of the population by bone marrow lesion (BML) status.

\begin{tabular}{lcc}
\hline Variable & $\begin{array}{c}\text { BML-negative, } \\
\mathrm{n}=108\end{array}$ & $\begin{array}{c}\text { BML-positive, } \\
\mathrm{n}=68\end{array}$ \\
\hline Age, yrs, mean (SD) & $61.4(7.5)$ & $62.9(7.6)$ \\
Body mass index at baseline, mean (SD) & $29.6(4.93)$ & $30.0(5.5)$ \\
Global WOMAC score, mean (SD) & $1027.3(518.3)$ & $1000.0(554.5)$ \\
VAS knee pain score, mean (SD) & $51.8(24.9)$ & $50.0(21.4)$ \\
Kellgren-Lawrence scale score, $\mathrm{n}(\%)$ & & \\
2 & $75(69)$ & $44(65)$ \\
3 & $33(31)$ & $24(35)$ \\
\hline
\end{tabular}

WOMAC: Western Ontario and McMaster Universities Osteoarthritis Index; VAS: visual analog scale.

baseline, men with KL grade 2 had greater JSW (3.98 mm) than women with the same KL grade (JSW $3.11 \mathrm{~mm}$ ), and the difference was statistically significant. Male JSW remained greater than in women throughout the remaining study timepoints, but the difference was no longer statistically significant by the end of the study. A similar pattern existed in those with KL grade 3: male JSW at baseline $(3.72 \mathrm{~mm})$ was greater than that of women with the same KL grade (JSW $2.98 \mathrm{~mm}$ ) and this pattern continued throughout the study period.

Table 3 presents the results of univariate regression analysis to assess determinants of change in JSW. The only significant determinant of change in JSW per year of followup was the presence of BML at baseline (Figure 2), and no significant relationship between the presence of other MRI findings (cartilage morphology, cartilage signal, cyst bursa, ligament abnormality, or osteophytes) and change in

$$
\text { Personal non-commercial use only. The Journal of Rheumatology Copyright } \odot \text { 2016. All rights reserved. }
$$




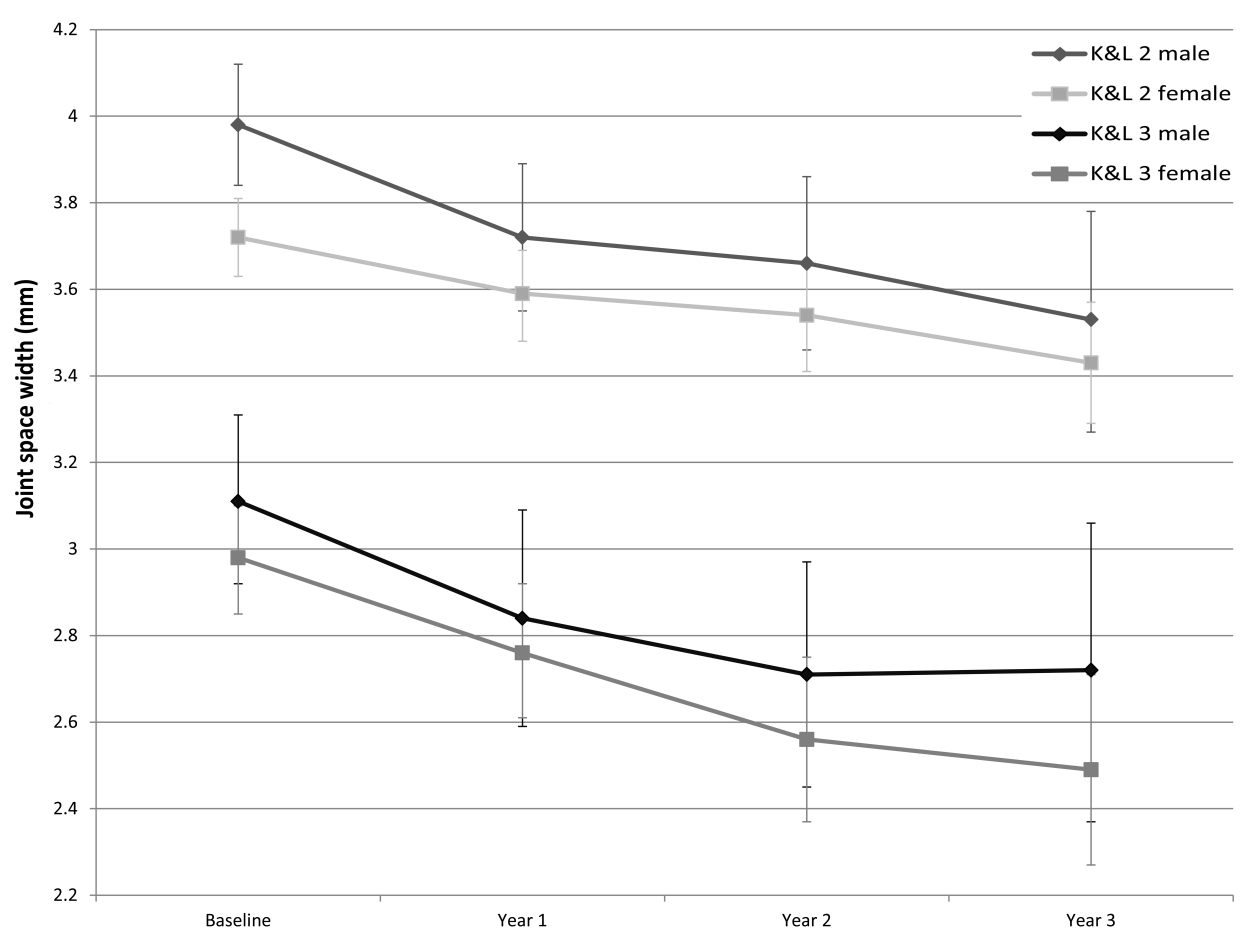

Figure 1. Mean joint space width (mm) and 95\% confidence interval over duration of study according to Kellgren and Lawrence grade and sex.

Table 3. Univariate associations between joint space variables and clinical features. Values are $\beta$ (95\% CI), with $\mathrm{p}$ values.

\begin{tabular}{cccc}
\hline & Men & Women & All \\
\hline Joint space reduction per year of followup & & \\
Age, yrs & $-0.001(-0.008,0.006)$ & $0.000(-0.004,0.003)$ & $-0.001(-0.004,0.002)$ \\
p & 0.758 & 0.832 & 0.622 \\
BMI at baseline & $0.001(-0.012,0.013)$ & $-0.002(-0.006,0.003)$ & $-0.001(-0.006,0.003)$ \\
p & 0.909 & 0.492 & 0.619 \\
KL grade & $-0.048(-0.149,0.053)$ & $-0.042(-0.095,0.011)$ & $-0.046(-0.094,0.003)$ \\
p & 0.353 & 0.12 & 0.064 \\
BML & $-0.180(-0.337,-0.022)$ & $-0.072(-0.163,0.020)$ & $-0.101(-0.180,-0.023)$ \\
p & 0.026 & 0.125 & 0.012 \\
Joint space width at baseline & & & \\
Age, yrs & $-0.011(-0.028,0.006)$ & $-0.010(-0.021,0.001)$ & $-0.009(-0.018,0.000)$ \\
p & 0.193 & 0.084 & 0.057 \\
BMI at baseline & $-0.003(-0.034,0.029)$ & $-0.014(-0.029,0.001)$ & $-0.012(-0.025,0.001)$ \\
p & 0.856 & 0.06 & 0.08 \\
KL grade & $-0.872(-1.104,-0.641)$ & $-0.743(-0.895,-0.592)$ & $-0.780(-0.907,-0.652)$ \\
p & $<0.001$ & $<0.001$ & $<0.001$ \\
BML & $-0.275(-0.764,0.214)$ & $0.051(-0.218,0.321)$ & $-0.020(-0.261,0.222)$ \\
p & 0.263 & 0.706 & 0.871 \\
\hline BI bon & & & \\
\hline
\end{tabular}

BMI: body mass index; KL: Kellgren-Lawrence; BML: bone marrow lesions.

JSW per year of followup was found. Interestingly, when men and women were assessed separately the association was significant only in the men, despite a larger female population in the study sample, suggesting this was not a power issue. No significant association was found between change in JSW per year of followup and baseline age, BMI (including analysis using thresholds $>30$ and $>35$ ), KL grade, or baseline VAS pain score. The relationship between change in JSW per year of followup and BML remained statistically significant after adjustment for age, sex, and KL grade $[\beta$ $=-0.10(95 \% \mathrm{CI}-0.18,-0.02)$; Table 4$]$. Therefore those with BML lost on average $0.10 \mathrm{~mm}$ per year more JSW than those without BML after other characteristics were accounted for. 
Table 4. Associations between joint space variables and clinical features after adjustment for age, sex, and mutual adjustment. Values are $\beta(95 \% \mathrm{CI})$, with $\mathrm{p}$ values.

\begin{tabular}{|c|c|c|}
\hline & $\begin{array}{l}\text { Joint Space Reduction, mm } \\
\text { per year of followup }\end{array}$ & $\begin{array}{c}\text { Joint Space Width, mm } \\
\text { at baseline }\end{array}$ \\
\hline KL grade $^{\mathrm{a}}$ & $-0.045(-0.09,0.00)$ & $-0.774(-0.90,-0.65)^{* *}$ \\
\hline $\mathrm{p}$ & 0.068 & $<0.001$ \\
\hline $\mathrm{BML}^{\mathrm{a}}$ & $-0.102(-0.18,-0.02)^{*}$ & $0.003(-0.24,0.24)$ \\
\hline $\mathrm{p}$ & 0.011 & 0.983 \\
\hline KL grade ${ }^{b}$ & $-0.044(-0.09,0.00)$ & $-0.782(-0.91,-0.66)^{* *}$ \\
\hline $\mathrm{p}$ & 0.074 & $<0.001$ \\
\hline $\mathrm{BML}^{\mathrm{b}}$ & $-0.103(-0.18,-0.02)^{*}$ & $-0.039(-0.27,0.20)$ \\
\hline $\mathrm{p}$ & 0.011 & 0.746 \\
\hline KL grade ${ }^{c}$ & $-0.043(-0.09,0.00)$ & $-0.776(-0.90,-0.65)^{* *}$ \\
\hline $\mathrm{p}$ & 0.077 & $<0.001$ \\
\hline $\mathrm{BML}^{\mathrm{c}}$ & $-0.103(-0.18,-0.02)^{*}$ & $-0.015(-0.25,0.22)$ \\
\hline $\mathrm{p}$ & 0.011 & 0.901 \\
\hline KL grade ${ }^{\mathrm{d}}$ & $-0.077(-0.16,0.01)$ & $-0.589(-0.82,-0.36)^{* *}$ \\
\hline $\mathrm{p}$ & 0.065 & $<0.001$ \\
\hline $\mathrm{BML}^{\mathrm{d}}$ & $-0.100(-0.18,-0.02)^{*}$ & $0.008(-0.21,0.23)$ \\
\hline $\mathrm{p}$ & 0.013 & 0.945 \\
\hline
\end{tabular}

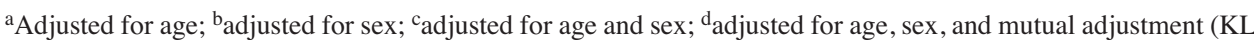
grade adjusted for BML and BML adjusted for KL grade); * $\mathrm{p}<0.05$; ** $\mathrm{p}<0.01$. BML: bone marrow lesions; KL: Kellgren-Lawrence.

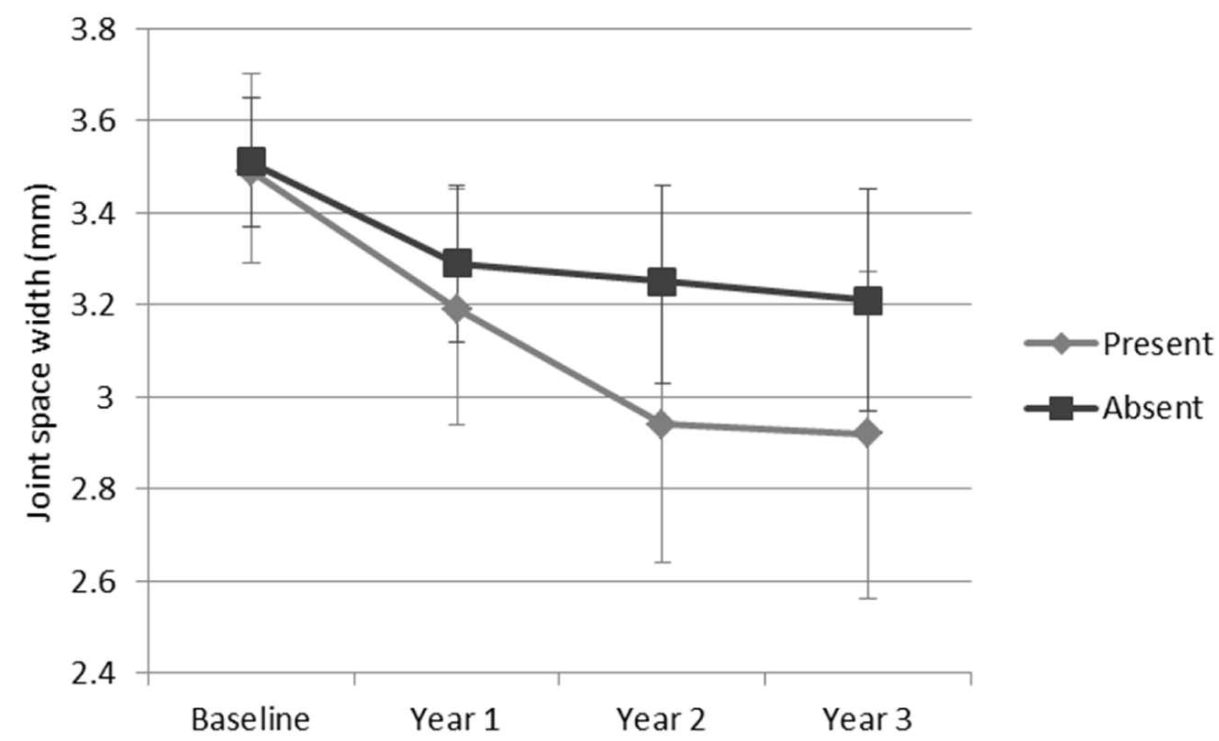

Figure 2. Mean joint space width $(\mathrm{mm})$ and $95 \%$ confidence interval over duration of the study according to presence of bone marrow lesions.

\section{DISCUSSION}

In this cohort of men and women with symptomatic radiographic OA, the presence of BML, and not other structural abnormalities visible on MRI at baseline, was a predictor of radiographic progression with higher rates of change in JSW. Adjustment for age, sex, and KL grade did not attenuate this finding, but when analyzed separately by sex, this was observed only in men. Conversely, age and BMI did not show predictive value. BML and cartilage abnormal- ities on MRI were common and prevalence did not differ significantly by sex. It is possible that our positive findings with BML only may reflect the 3-dimensional nature of MRI, in contrast to the 2-dimensional nature of radiographs. While adjustment for multiple testing was undertaken, and raises the possibility of a chance finding, our results are in accord with those in the literature ${ }^{23}$. The rate of change in JSW was independent of baseline KL score in univariate analyses, with an overall mean rate of change in JSW of $0.15 \mathrm{~mm}$ per year.

$$
\text { Personal non-commercial use only. The Journal of Rheumatology Copyright @ } 2016 \text {. All rights reserved. }
$$


Consequently, JSW remained lower throughout the study in those with the higher KL grade at baseline. Interestingly, JSW was persistently lower in women than men, although this difference reached statistical significance only at baseline in those with a KL score of 2 (Figure 1).

Disease progression in OA can be a slow process. Rate of joint space loss is important in this process and remains a recommended outcome for trials of structure modification ${ }^{34}$. Over the 3 years of our study, we observed a mean annualized joint space narrowing (JSN) of $0.15 \mathrm{~mm}$. This is in keeping with previous studies of radiographic OA. A review by Emrani and colleagues identified 27 studies that had estimated rates of JSN, all of which were smaller than our current study (between 11 and 312 participants), with comparable mean followup $(26 \pm 14 \mathrm{mo})^{35}$. They found that changes in joint space estimates ranged from an increase of $0.1 \mathrm{~mm} /$ year to a decrease of $0.7 \mathrm{~mm} /$ year. The mean finding across all studies was $0.13 \pm 15 \mathrm{~mm} / \mathrm{year}$.

In the Chingford Women's Study, the natural history of radiographic OA was investigated over 15 years in women aged 44-67 years, although KL grade was used instead of joint space, making comparison with our results more difficult ${ }^{36}$. On average, $2.3 \%$ of women with a baseline KL of 0 or 1 progressed to radiographic $\mathrm{OA}(\mathrm{KL} \geq 2)$ per year. Their rates of OA progression were $2.8 \%$ per year $^{36}$. These are similar to results from the Framingham Osteoarthritis Study (4\%) and a study by Cooper, et al (3.6\%), both of which investigated men and women ${ }^{5,9}$. Much higher rates were found in a small 12-year Swedish cohort in whom around $8 \%$ progressed per year; this equated to all individuals studied progressing during followup ${ }^{37}$.

Many risk factors for OA progression have been studied, with inconsistent findings. When age was investigated, several studies found no association with rate of progression $^{6,9,38}$, whereas studies by Miyazaki, et al and Schouten, et al found higher rates of progression in older individuals ${ }^{4,8}$. Our results are in keeping with the former, providing no evidence for such a relationship.

The findings of studies that investigated sex as a predictor of OA progression are more consistent. Multiple potential OA progression outcomes have been assessed including change in KL grade, JSN, osteophytosis, and sclerosis, with no evidence of a modifying effect of $\operatorname{sex}^{3,4,6,7,8,9}$. We too observed similar patterns of JSN by KL score in men and women (Figure 1). Interestingly, Ledingham and colleagues additionally investigated predictors of change in cyst numbers, and did find the rate was higher in women ${ }^{3}$. Of note, when we analyzed the relationship between BML and radiographic progression separately by sex, this was significant only in men. The possibility of sexual dimorphism requires replication in other larger samples, but may reflect different pathophysiology in the 2 sexes.

BMI would appear to be a good candidate to promote disease progression in OA. However, results of several studies, including our own, have not borne this out ${ }^{6,8}$. Cooper, et $a l^{5}$ demonstrated a predictive role for BMI comparing highest and lowest tertiles in a subgroup of individuals with $\mathrm{KL} \geq 2$, although in those with $\mathrm{KL} \geq 1$ the relationship was not replicated ${ }^{5}$. Other investigators have shown associations of borderline significance ${ }^{3,7}$.

Assessing baseline radiographic severity as a predictor of progression rate, Miyazaki, et al and Pavelka, et al observed no significant association between baseline JSN and OA progression $^{8,39}$. Further, Bruyere, et al did find a borderline reduction of risk, for JSN of $0.5 \mathrm{~mm}$ over 3 years, in those in the lowest quartile for joint space at baseline, but this did not reach statistical significance ${ }^{40}$. In accord with these findings, our study showed that baseline KL score did not predict rate of JSN in univariate or multivariate analysis (Table 4). We also showed that those with the highest KL scores at baseline maintained the lowest JSW throughout the study (Figure 1). This is commensurate with the work of Wolfe and Lane ${ }^{7}$, who showed that those with greater baseline disease severity were more likely to progress to the highest severity score of JSN 7 .

$\mathrm{BML}$, as seen on MRI, provide evidence of bone marrow edema, fibrosis, necrosis, and trabecular abnormalities on histopathologic examination ${ }^{14}$. We found strong associations between the presence of these lesions and the rate of change of JSW. A similar study to our own by Felson, et al showed analogous results ${ }^{23}$. Although the age and BMI characteristics of participants were comparable, their study differed in that it included individuals with any KL grade; and progression was defined as an increase in grade of JSN (0-3) in a compartment-specific manner rather than using JSW as a continuous variable for the joint as a whole. Despite these differences of design the findings were very similar, strengthening the likelihood of a true association.

Despite the inconsistent relationship between MRI cartilage morphology and radiographic joint space in $\mathrm{OA}^{41}$, those studies that focused on MRI outcomes rather than radiographic changes have provided useful complementary evidence. A higher baseline BML score has been shown to be associated with greater MRI-defined cartilage $\operatorname{loss}{ }^{42,43,44,45}$, and those in whom the BML progressed were at even higher risk ${ }^{44}$. Kubota, et al showed that a subgroup with a KL grade of 1 at baseline had larger BML at baseline. However, this was not found in those of KL grade 2 or $3^{46}$. Further, Kothari, et $a l^{47}$ investigated whether there was localization of both BML and cartilage loss within the same subregions of the joint, as assessed by $\mathrm{MRI}^{47}$. They found that BML predicted greater subregional cartilage loss at the corresponding site after accounting for other co-localized bone lesions, suggesting a direct local effect. The precise mechanism by which BML influence the disease process is not fully understood.

There are limitations to our study. As it was conducted over a large number of centers in many countries, variability may have been introduced. However, a strength of this particular

Personal non-commercial use only. The Journal of Rheumatology Copyright (C) 2016. All rights reserved. 
cohort is that it represents the control arm of a randomized controlled trial, with the associated safeguards around methodology and training. Using only the placebo arm of the randomized controlled trial to assess risk factors for progression may have introduced collider bias into the analysis; however, the findings are in keeping with previous literature. The study excluded individuals with KL grade 4 and those receiving drugs that affect cartilage or bone metabolism; this may limit the generalizability of the study results, in particular with regard to the overall descriptive epidemiology of JSN in OA. Individuals without joint pain were also excluded, which might explain the lack of difference in knee pain scores between those with and those without BML at baseline. Further, as with any study of this type, potential causes of radiographic JSN other than cartilage thinning, such as meniscal extrusion, cannot be excluded as causes for the changes that were observed. However, complete meniscal extrusions were noted in only 4 individuals and other MRI findings (cartilage morphology, cartilage signal, cyst bursae, ligament abnormality, and osteophytes) were found not to be univariately associated with JSN. It would have been preferable to use Osteoarthritis Research Society International (OARSI) medial JSN to look at the relationship with (medial) radiographic progression, and to look at results using medial JSN for adjustment rather than KL grade. Unfortunately, OARSI grades were not recorded in this study. Finally, we were unable to consider a large number of determinants of progression in our models; specifically, more detailed information about fat mass and fat distribution would have been interesting to consider, but was unavailable in this cohort.

We observed an average rate of JSN in individuals with symptomatic radiographic OA of $0.15 \mathrm{~mm} /$ year, consistent with the literature. Age, sex, and BMI did not significantly influence the disease course, whereas BML, which were common in our cohort, were the only baseline MRI finding associated with more rapid radiographic deterioration. This is commensurate with studies of predictors of MRI-assessed cartilage loss and may highlight an important factor in the pathogenesis of OA disease progression. However, there is insufficient evidence to suggest that a treatment targeting these lesions would ameliorate cartilage loss.

\section{ACKNOWLEDGMENT}

We acknowledge the directors and personnel of the 23 investigating centers and all members of the SEKOIA management team.

\footnotetext{
APPENDIX 1.

List of study collaborators. SEKOIA Study Group: Executive Committee: J-Y. Reginster (Chair), C. Cooper (International Coordinator), C. Christiansen, P. Delmas (deceased July 2008), R. Chapurlat (from 2008 onward), H. Genant, J. Zacher, N. Bellamy. Steering Committee: C. Cooper (International Coordination, Chair), National Coordinators (see below), and representatives from the central reading centers. Safety Committee: C. Speirs, G. Bréart, O. Meyer. Central Reading Centre (Lyon): D. Gensburger, M. Arlot, J-P. Roux, R. Chapurlat. Central Reading Centre (Liege): R. Deroisy, O. Bruyère, J-Y. Reginster. National Coordinators: P. Sambrook (Australia), B. Leeb (Austria), A. Verbruggen (Belgium), W. Bensen
}

(Canada), T. Hala (Czech Republic), M. Holm-Bentzen (Denmark), I. Valter (Estonia), X. Chevalier (France), B. Swoboda (Germany), S. Adami (Italy), M. Kloppenburg (The Netherlands), E. Grazuleviciute (Lithuania), J. Badurski (Poland), J. Branco (Portugal), E. Nasonov (Russia), F. Navarro (Spain), T. Spector (UK). Investigators: Australia: L. Barnsley, S. Hall, G. Jones, A. Klestov, L. March, P. Nash, E. Romas, R. Will; Austria: L. Erlacher, F.B. Leeb, H. Resch, F. Rainer, O. Zamani; Belgium: T. Appelboom, J.P. Devogelaer, A. Kvasz, F. Raeman, A. Verbruggen; Canada: A.D. Beaulieu, W.G. Bensen, J. Brown, A.A. Cividino, F. Morin, W.P. Olszynski, J.P. Raynauld, J.C. Thorne; Czech Republic: T. Hala, K. Pavelka; Denmark: P. Alexandersen, H.C. Hoeck, M. Holm-Bentzen, P. Lundqvist; Estonia: I. Valter; France: L. Aim, P. Audouy, P. Beaunier, C.L. Benhamou, F. Berenbaum, E. Chabaud, D. Chalet, X. Chevalier, M. Cohen-Solal, D. Delbecq, L. Euller-Ziegler, P. Fardellone, P. Hilliquin, E. Jacquety, N. Jude, D. Lechevalier, J.C. Mouchet, P. Richette, E. de Sainte Lorette, T. Schaeverbeke, A. Sebbah, E. Vignot; Germany: T. Brabant, G.R. Burmester, J. Grifka, P.E.M. Müller, B. Swoboda, J. Zacher; Italy: S. Adami, G. Bianchi, W. Grassi, L. Di Matteo, V. Modena, O. Di Munno, S. Ortolani, L. Punzi, M. Zangari; Lithuania: E. Grazuleviciute; Netherlands: M. Kloppenburg, L.D. Roorda, P.L.C.M. Van Riel; Poland: J. Badurski, E. Czerwinski, A. Gorecki, W. Tlustochowicz; Portugal: J. Branco, J. Canas Da Silva, J.A. Melo Gomes, L.M. Miranda; Romania: F. Radulescu; Russian Federation: L.I. Alexeeva, A.V. Orlov-Morozov, E.G. Pikhlak, V.G. Pilyaev, N.A. Shostak, E.I. Shmidt, N.V. Zagorodniy; Spain: L. Arboleya Rodríguez, P. Benito Ruiz, E. Chamizo Carmona, E. Collantes Estévez, G. Herrero-Beaumont, E. Martín Mola, A. Moreno, A. Naranjo Hernández, F. Navarro Sarabia, J.M. Padrino, C. Palacios, A. Rodríguez de la Serna, J.A. Román Ivorra, A. Torrijos; United Kingdom: E. Abdulhakim, N. Arden, F. Birrell, H. Donnachie, W. Fraser, R. Keen, R. Sarmiento, M.D. Stone.

\section{REFERENCES}

1. Michaud CM, McKenna MT, Begg S, Tomijima N, Majmudar M, Bulzacchelli MT, et al. The burden of disease and injury in the United States 1996. Popul Health Metr 2006;4:11

2. Belo JN, Berger MY, Reijman M, Koes BW, Bierma-Zeinstra SM. Prognostic factors of progression of osteoarthritis of the knee: A systematic review of observational studies. Arthritis Rheum 2007;57:13-26.

3. Ledingham J, Regan M, Jones A, Doherty M. Factors affecting radiographic progression of knee osteoarthritis. Ann Rheum Dis 1995;54:53-8

4. Schouten JS, van den Ouweland FA, Valkenburg HA. A 12 year follow up study in the general population on prognostic factors of cartilage loss in osteoarthritis of the knee. Ann Rheum Dis 1992;51:932-7.

5. Cooper C, Snow S, McAlindon TE, Kellingray S, Stuart B, Coggon $\mathrm{D}$, et al. Risk factors for the incidence and progression of radiographic knee osteoarthritis. Arthritis Rheum 2000;43:995-1000.

6. Dieppe P, Cushnaghan J, Young P, Kirwan J. Prediction of the progression of joint space narrowing in osteoarthritis of the knee by bone scintigraphy. Ann Rheum Dis 1993;52:557-63.

7. Wolfe F, Lane NE. The longterm outcome of osteoarthritis: Rates and predictors of joint space narrowing in symptomatic patients with knee osteoarthritis. J Rheumatol 2002;29:139-46.

8. Miyazaki T, Wada M, Kawahara H, Sato M, Baba H, Shimada S. Dynamic load at baseline can predict radiographic disease progression in medial compartment knee osteoarthritis. Ann Rheum Dis 2002;61:617-22.

9. Felson DT, Zhang Y, Hannan MT, Naimark A, Weissman BN, Aliabadi $\mathrm{P}$, et al. The incidence and natural history of knee osteoarthritis in the elderly. The Framingham Osteoarthritis Study. Arthritis Rheum 1995;38:1500-5.

10. Huffman KM, Kraus WE. Osteoarthritis and the metabolic syndrome: More evidence that the etiology of OA is different in men and women. Osteoarthritis Cartilage 2012;20:603-4.

11. Roemer FW, Guermazi A, Niu J, Zhang Y, Mohr A, Felson DT.

Personal non-commercial use only. The Journal of Rheumatology Copyright @ 2016. All rights reserved. 
Prevalence of magnetic resonance imaging-defined atrophic and hypertrophic phenotypes of knee osteoarthritis in a population-based cohort. Arthritis Rheumatism 2012;64:429-37.

12. Hayashi D, Guermazi A, Kwoh CK, Hannon MJ, Moore C, Jakicic $\mathrm{JM}$, et al. Semiquantitative assessment of subchondral bone marrow edema-like lesions and subchondral cysts of the knee at 3T MRI: A comparison between intermediate-weighted fat-suppressed spin echo and dual echo steady state sequences. BMC Musculoskel Disord 2011;12:198.

13. Xu L, Hayashi D, Roemer FW, Felson DT, Guermazi A. Magnetic resonance imaging of subchondral bone marrow lesions in association with osteoarthritis. Semin Arthritis Rheum 2012; 42:105-18

14. Zanetti M, Bruder E, Romero J, Hodler J. Bone marrow edema pattern in osteoarthritic knees: Correlation between MR imaging and histologic findings. Radiology 2000;215:835-40.

15. Felson DT, Chaisson CE, Hill CL, Totterman SM, Gale ME, Skinner $\mathrm{KM}$, et al. The association of bone marrow lesions with pain in knee osteoarthritis. Ann Intern Med 2001;134:541-9.

16. Bollet AJ. Edema of the bone marrow can cause pain in osteoarthritis and other diseases of bone and joints. Ann Intern Med 2001;134:591-3.

17. Zhai G, Blizzard L, Srikanth V, Ding C, Cooley H, Cicuttini F, et al. Correlates of knee pain in older adults: Tasmanian Older Adult Cohort Study. Arthritis Rheum 2006;55:264-71

18. Phan CM, Link TM, Blumenkrantz G, Dunn TC, Ries MD, Steinbach LS, et al. MR imaging findings in the follow-up of patients with different stages of knee osteoarthritis and the correlation with clinical symptoms. Eur Radiol 2006;16:608-18.

19. Zhang Y, Nevitt M, Niu J, Lewis C, Torner J, Guermazi A, et al. Fluctuation of knee pain and changes in bone marrow lesions, effusions, and synovitis on magnetic resonance imaging. Arthritis Rheum 2011;63:691-9.

20. Pessis E, Drape JL, Ravaud P, Chevrot A, Dougados M, Ayral X. Assessment of progression in knee osteoarthritis: Results of a 1 year study comparing arthroscopy and MRI. Osteoarthritis Cartilage 2003;11:361-9.

21. Wluka AE, Wang Y, Davies-Tuck M, English DR, Giles GG, Cicuttini FM. Bone marrow lesions predict progression of cartilage defects and loss of cartilage volume in healthy middle-aged adults without knee pain over 2 yrs. Rheumatology 2008;47:1392-6.

22. Davies-Tuck ML, Wluka AE, Forbes A, Wang Y, English DR, Giles GG, et al. Development of bone marrow lesions is associated with adverse effects on knee cartilage while resolution is associated with improvement - A potential target for prevention of knee osteoarthritis: A longitudinal study. Arthritis Res Ther 2010;12:R10.

23. Felson DT, McLaughlin S, Goggins J, LaValley MP, Gale ME, Totterman $\mathrm{S}$, et al. Bone marrow edema and its relation to progression of knee osteoarthritis. Ann Intern Med 2003;139:330-6.

24. Cooper C, Reginster JY, Chapurlat R, Christiansen C, Genant H, Bellamy N, et al. Efficacy and safety of oral strontium ranelate for the treatment of knee osteoarthritis: Rationale and design of randomised, double-blind, placebo-controlled trial. Curr Med Res Opin 2012;28:231-9.

25. Altman R, Asch E, Bloch D, Bole G, Borenstein D, Brandt K, et al. Development of criteria for the classification and reporting of osteoarthritis. Classification of osteoarthritis of the knee. Diagnostic and Therapeutic Criteria Committee of the American Rheumatism Association. Arthritis Rheum 1986;29:1039-49.

26. Kellgren JH, Lawrence JS. Radiological assessment of osteo-arthrosis. Ann Rheum Dis 1957;16:494-502.

27. Kothari M, Guermazi A, von Ingersleben G, Miaux Y, Sieffert M, Block JE, et al. Fixed-flexion radiography of the knee provides reproducible joint space width measurements in osteoarthritis. Eur Radiol 2004;14:1568-73.
28. Gensburger D, Roux JP, Arlot M, Sornay-Rendu E, Ravaud P, Chapurlat R. Influence of blinding sequence of radiographs on the reproducibility and sensitivity to change of joint space width measurement in knee osteoarthritis. Arthritis Care Res 2010;62:1699-705.

29. Botha-Scheepers S, Watt I, Breedveld FC, Kloppenburg M. Reading radiographs in pairs or in chronological order influences radiological progression in osteoarthritis. Rheumatology 2005; 44:1452-5.

30. Felson DT, Nevitt MC. Blinding images to sequence in osteoarthritis: Evidence from other diseases. Osteoarthritis Cartilage 2009;17:281-3

31. Gensburger D, Arlot M, Sornay-Rendu E, Roux JP, Delmas P. Radiologic assessment of age-related knee joint space changes in women: A 4-year longitudinal study. Arthritis Rheum 2009; 61:336-43.

32. Peterfy CG, Guermazi A, Zaim S, Tirman PF, Miaux Y, White D, et al. Whole-Organ Magnetic Resonance Imaging Score (WORMS) of the knee in osteoarthritis. Osteoarthritis Cartilage 2004;12:177-90.

33. Declaration of Helsinki. Ethical principles for medical research involving human subjects. J Ind Med Assoc 2009;107:403-5.

34. Conaghan PG, Hunter DJ, Maillefert JF, Reichmann WM, Losina E. Summary and recommendations of the OARSI FDA osteoarthritis Assessment of Structural Change Working Group. Osteoarthritis Cartilage 2011;19:606-10.

35. Emrani PS, Katz JN, Kessler CL, Reichmann WM, Wright EA, McAlindon TE, et al. Joint space narrowing and Kellgren-Lawrence progression in knee osteoarthritis: An analytic literature synthesis. Osteoarthritis Cartilage 2008;16:873-82.

36. Leyland KM, Hart DJ, Javaid MK, Judge A, Kiran A, Soni A, et al. The natural history of radiographic knee osteoarthritis: A fourteen-year population-based cohort study. Arthritis Rheum 2012;64:2243-51.

37. Thorstensson CA, Andersson ML, Jonsson H, Saxne T, Petersson IF Natural course of knee osteoarthritis in middle-aged subjects with knee pain: 12-year follow-up using clinical and radiographic criteria. Ann Rheum Dis 2009;68:1890-3.

38. Bagge E, Bjelle A, Svanborg A. Radiographic osteoarthritis in the elderly. A cohort comparison and a longitudinal study of the "70-year old people in Goteborg". Clin Rheumatol 1992;11:486-91.

39. Pavelka K, Gatterova J, Altman RD. Radiographic progression of knee osteoarthritis in a Czech cohort. Clin Exp Rheumatol 2000;18:473-7.

40. Bruyere O, Honore A, Ethgen O, Rovati LC, Giacovelli G, Henrotin YE, et al. Correlation between radiographic severity of knee osteoarthritis and future disease progression. Results from a 3-year prospective, placebo-controlled study evaluating the effect of glucosamine sulfate. Osteoarthritis Cartilage 2003;11:1-5.

41. Hunter DJ, Zhang W, Conaghan PG, Hirko K, Menashe L, Li L, et al. Systematic review of the concurrent and predictive validity of MRI biomarkers in OA. Osteoarthritis Cartilage 2011;19:557-88.

42. Hunter DJ, Zhang Y, Niu J, Goggins J, Amin S, LaValley MP, et al. Increase in bone marrow lesions associated with cartilage loss: A longitudinal magnetic resonance imaging study of knee osteoarthritis. Arthritis Rheum 2006;54:1529-35.

43. Tanamas SK, Wluka AE, Pelletier JP, Pelletier JM, Abram F, Berry PA, et al. Bone marrow lesions in people with knee osteoarthritis predict progression of disease and joint replacement: A longitudinal study. Rheumatology 2010;49:2413-9.

44. Roemer FW, Guermazi A, Javaid MK, Lynch JA, Niu J, Zhang Y, et al. Change in MRI-detected subchondral bone marrow lesions is associated with cartilage loss: The MOST Study. A longitudinal multicentre study of knee osteoarthritis. Ann Rheum Dis 2009;68:1461-5.

45. Dore D, Martens A, Quinn S, Ding C, Winzenberg T, Zhai G, et al. 
Bone marrow lesions predict site-specific cartilage defect development and volume loss: A prospective study in older adults. Arthritis Res Ther 2010;12:R222.

46. Kubota M, Ishijima M, Kurosawa H, Liu L, Ikeda H, Osawa A, et al. A longitudinal study of the relationship between the status of bone marrow abnormalities and progression of knee osteoarthritis. J Orthop Sci 2010;15:641-6.
47. Kothari A, Guermazi A, Chmiel JS, Dunlop D, Song J, Almagor O, et al. Within-subregion relationship between bone marrow lesions and subsequent cartilage loss in knee osteoarthritis. Arthritis Care Res 2010;62:198-203. 